\title{
Helen Ollendorff Curth and Curth-Macklin Syndrome
}

\author{
Khalid Al Aboud ${ }^{*}, 1$ and Daifullah Al Aboud ${ }^{2}$ \\ ${ }^{I}$ Dermatology Department, King Faisal Hospital, Makkah, Saudi Arabia \\ ${ }^{2}$ Dermatology Department, Taif University, Taif, Saudi Arabia
}

\begin{abstract}
Helen Ollendorff Curth (1899-1982), is one of the pioneers in dermatology. In 1954, she and Madge Thurlow Macklin (1893-1962), an American medical geneticist, reported, a rare congenital genodermatosis that was later known as Curth-Macklin syndrome. This syndrome is a rare autosomal dominant skin disorder characterized by extensive hyperkeratosis and palmo-plantar keratoderma.
\end{abstract}

This report shed light on Helene Ollendorff Curth and the Curth-Macklin syndrome.

Keywords: Dermatology, ichthyosis, skin.

Helene Ollendorff Curth (1899-1982), (Fig. 1) is one of the renown Jewish dermatologists [1-4]. Among her great contributions to dermatology, she is credited for his contribution in describing a syndrome [5], that was later known as Ichthyosis Hystrix, Curth-Macklin type (IHCM) [6-12]. This report shed light on Helene Ollendorff Curth and the Curth-Macklin syndrome.

Ichthyoses refer to a heterogeneous group of inherited skin diseases characterized clinically by skin hyperkeratosis, skin scaling, or both.

These disorders are undergoing reclassification away from clinical presentation to pathogenesis as outlined by a recent consensus [8].

Ichthyosis Hystrix (IH) is a group of skin disorders with massive hyperkeratosis that has a verrucous surface [12]. Four different types of IH have been described: Lambert type, Curth-Macklin type, Rheydt type, and Bafverstedt type [12].

IHCM (OMIM\#146590), also known as congenital reticulate ichthyosiform erythroderma [3].

IHCM is a rare autosomal dominant skin disorder characterized by extensive hyperkeratosis and palmo-plantar keratoderma. IHCM was investigated by immunohistochemistry and electron microscopy and the results suggest that there is no prematurity of keratinization, but rather a pathological expression of specific keratin genes leading to expression of fetal keratins in this form of ichthyosis hystrix [7].

It results from heterozygous frameshift mutation in keratin 1 gene (KRT1) and a new mutation for this disease is recently reported [6].

Histological features of this disorder are perinuclear vacuolization and binucleated cells, which are similar to

*Address correspondence to this author at the Dermatology Department, King Faisal Hospital, P.O Box 5440, Makkah 21955, Saudi Arabia;

Tel: +966 2 5566411, Ext. 1110; Fax: +966 2 5563523;

E-mailamoa65@hotmail.com those of epidermolytic hyperkeratosis except for the absence of epidermolysis [12].

In IHCM, there are horny or velvety spikes rather than thickened scales. Hystrix is from the Greek word for quills or spines, as in a porcupine [4]. Ultrastructurally, IHCM is characterized by disruption of the keratin intermediate filament network of suprabasal keratinocytes. Blister formation does not occur [11].

IHCM presents with striate or diffuse PPK. The course of the disease is characterized by progressive worsening of PPK and development of hyperkeratotic plaques over joints and/or hyperkeratotic papules on trunk and extremities [8].

This disorder have been reported sporadically as a single case [12] and in families [11]. In one of the families reported, the patients had thick, furrowed-appearing hyperkeratosis over joints [10].

KRT1 frameshift mutations at almost the same position have been found in IHCM and in striate palmoplantar keratoderma III (SPPK3; OMIM 607654). Some authors found normal desmosome formation in IHCM, suggesting that the cytopathologic effects leading to hyperkeratosis and PPK in this disorder differ from those in SPPK, and may be related to abnormalities in supramolecular keratin intermediate filament organization and cytoplasmic trafficking of insoluble proteins, such as loricrin, as suggested by other authors [11]. It has also been suggested that, it is also possible that mutant KRT1 affects shapes of the cells and integrity of other cellular structures, such as organelles and the nucleus, leading to gross alteration in the overall structures of the epidermis [11].

IHCM is named after Helen Ollendorff Curth and Madge Thurlow Macklin, who reported this disorder in 1954. IHCM was subsequently studied by Ingrun Anton-Lamprecht, who was able to identify unique ultrastructural features (unbroken concentric shells of tonofibrils around the nucleus, and up to $30 \%$ of the keratinocytes above the basal layer with two nuclei), which established the uniqueness of Curth-Macklin ichthyosis [4]. 

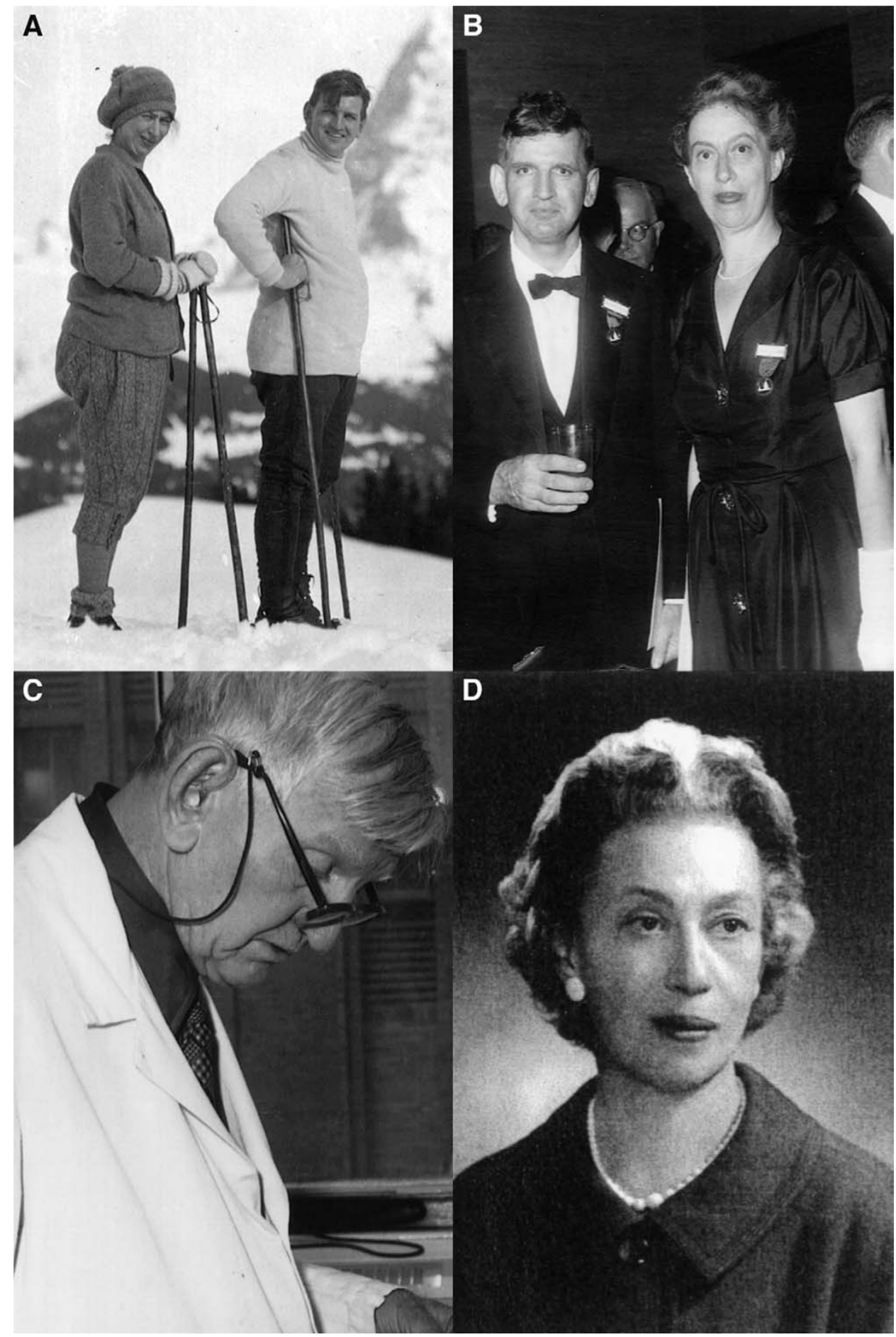

Fig. (1). Helen Ollendorff Curth and her husband on a ski trip in 1927. B, The couple in formal attire at a medical Congress in the mid1950s. C, William Curth in the clinic at Columbia in the 1960s. D, Helen Ollendorff Curth in a formal portrait in the 1960s.This figure is reproduced with permission from ref. [4].

IHCM is one of the first syndromes named after two women [4]. Macklin was an American medical geneticist (1893-1962) who made a name for herself in the research of hereditary aspects of cancer. She was instrumental in introducing the study of genetics into medical curricula [3], but she is also remembered for a continuing interest in eugenics, even after World War II [4].
Helene Ollendorff Curth is German-American dermatologist, born February 28, 1899, Breslau. In the United States her first name was Helen [1].

Helene Ollendorff Curth's most important work was on acanthosis nigricans. Another area of special interest to Helen Ollendorff Curth was the disorders of keratinization [4]. 
Helene Ollendorff studied medicine at the universities of Freiburg, Munich and Breslau, after qualifying in 1923 she trained in dermatology at the Rudolf-Virchow-Krankenhaus in Berlin under Abraham Buschke. She became Buschke's assistant subsequently married his other assistant, Wilhelm Curth.

The Curths moved to the USA in 1931 and commenced private practice in New York [1].

Burgdorf and Scholz have published a comprehensive essay about this couple [4], from which we are quoting the following paragraphs.

"Helen Ollendorff Curth was ahead of her times in many ways. For example, she was one of the first women to make a reputation in academic dermatology. She is one half of the first well-known husband and wife team in dermatology. She is one of the first dermatologists with a specific interest in genodermatoses. She is, also, one of very few physicians to have one eponymic syndrome with her maiden name attached (she and her mentor described dermatofibrosis lenticularis disseminata and osteopathia condensans disseminata—known today as Buschke-Ollendorff syndrome) and another with her married name (IHCM), as well as an eponymic sign (Ollendorff probe sign, the extreme sensitivity of syphilitic lesions to pressure with a dull probe), which is not currently used.

Helen Ollendorff Curth developed Alzheimer disease and, being aware of the finality of this strange assassin, willed her brain to Columbia University for much needed research on the topic. After her death on June 17, 1982, studies confirmed the presence of amyloid brain plaques."

\section{REFERENCES}

[1] Helene Ollendorff Curth. [A page on the Internet]. From Whonamedit? (C) 1994 - 2011 Ole Daniel Enersen. [This page was last modified, not mentioned; cited 2011 April 5]. Available at; http://www.whonamedit.com/doctor.cfm/1703.html

[2] Gorlin RJ. Helen Ollendorff Curth, on her 70th birthday. Hastert 1969; 20(2): 95.

[3] Strous RD, Edelman MC. Eponyms and the Nazi Era: Time to Remember and Time for Change. Medicine and the Holocaust. IMAJ 2007; 9: 207-14.

[4] Burgdorf WHC, Scholz A. Helen Ollendorff Curth and William Curth: From Breslau and Berlin to Bar Harbor. J Am Acad Derm 2004; 51(1): 84-9.

[5] Curth HO, Macklin MT. The genetic basis of various types of ichthyosis in a family group. Am J Hum Genet 1954; 6: 371-81.

[6] Kubo Y, Urano Y, Matsuda R, et al. Ichthyosis hystrix, CurthMacklin type: a new sporadic case with a novel mutation of keratin 1. Arch Dermatol. 2011; 147(8): 999-1001.

[7] Niemi KM, Virtanen I, Kanerva L, Muttilainen M. Altered keratin expression in ichthyosis hystrix Curth-Macklin. A light and electron microscopic study. Arch Dermatol Res 1990; 282(4): 22733.

[8] Oji V, Tadini G, Akiyama M, et al. Revised nomenclature and classification of inherited ichthyoses: results of the First Ichthyosis Consensus Conference in Sorèze 2009. J Am Acad Dermatol 2010; 63(4): 607-41.

[9] Ollendorff-Curth H, Allen FH Jr, Schnyder UW, Anton-Lamprecht I. Follow-up of a family suffering from ichthyosis hystrix type Curth-Macklin. Humangenetik 1972; 17: 37-48.

[10] Anton-Lamprecht I, Curth HO, Schnyder UW. Zur Ultrastruktur heredita"rer Verhornungssto" rungen II. Ichthyosis hystrix type Curth-Macklin. Arch Dermatol Forsch 1973; 346: 77-91.

[11] Ichthyosis Hystrix, Curth-Macklin type; IHCM. [A page on the Internet]. From OMIM, Online Mendelian Inheritance in Man. Copyright (c) 1966-2011 Johns Hopkins University [This page was last modified 2010 July 13; cited 2011 April 5]. Available at; http://www.ncbi.nlm.nih.gov/omim/146590

[12] Yusuf SM, Mijinyawa MS, Maiyaki MB, Mohammed AZ. Ichthyosis hystrix Curth-Macklin type in an African girl. Int $\mathbf{J}$ Dermatol. 2009; 48(12): 1343-5. 